\title{
IMOBILIZAÇÃO COVALENTE MULTIPONTUAL E CARACTERIZAÇÃO PARCIAL DA LIPASE DE Aspergillus niger EM PÓ DE SABUGO DE MILHO.
}

\author{
V. G. BATISTA ${ }^{1}$, R. MONTI ${ }^{2}$, J. P. M. GALÁN ${ }^{3}$, A. V. DE PAULA ${ }^{4}$ \\ ${ }^{1}$ Univ Estadual Paulista, UNESP, Faculdade de Ciências Farmacêuticas \\ ${ }^{2}$ Univ Estadual Paulista, UNESP, Departamento de Alimentos e Nutrição \\ ${ }^{3}$ Universidad de Antioquia, UdeA, Escuela de Nutrición y Dietética \\ ${ }^{4}$ Univ Estadual Paulista, UNESP, Departamento de Bioprocessos e Biotecnologia \\ E-mail para contato: viguerso97@gmail.com, ariela@fcfar.unesp.br
}

\begin{abstract}
RESUMO - O Brasil é um dos maiores produtores de milho do mundo e o grande volume de produção implica na geração de muitos resíduos. Um deles é o pó do sabugo, um material lignocelulósico com grande potencial para ser utilizado como suporte em imobilização de enzimas. Neste contexto, este trabalho teve por objetivo imobilizar a lipase de Aspergillus niger em pó de sabugo de milho, empregando-se o método de ligação covalente multipontual, e caracterizar o derivado imobilizado com relação aos seus valores ótimos de $\mathrm{pH}$, temperatura e estabilidade (térmica e ao $\mathrm{pH}$ ). Para isso, o suporte utilizado foi previamente funcionalizado com grupamentos glioxil, fornecendo um rendimento de imobilização de $39 \%$. O derivado imobilizado por ligação covalente apresentou $\mathrm{pH}$ ótimo de 6,5 e temperatura ótima de $35^{\circ} \mathrm{C}$. Com relação à estabilidade térmica, o biocatalisador apresentou maior estabilidade em temperaturas de até $45^{\circ} \mathrm{C}$. Finalmente, o biocatalisador apresentou boa estabilidade em faixas de $\mathrm{pH}$ alcalino. Portanto, esta metodologia de imobilização mostrou-se adequada para imobilização da lipase de Aspergillus niger, permitindo a obtenção de um derivado imobilizado com satisfatória estabilidade.
\end{abstract}

\section{INTRODUÇÃO:}

A utilização de enzimas em processos industriais é vantajosa, pois possibilita a redução da geração de rejeitos industriais prejudiciais ao meio ambiente e promove economia em energia e preservação dos tanques reacionais, uma vez que estes biocatalisadores não necessitam de altas temperaturas e pressões (SAID; PIETRO, 2014).

Uma das enzimas mais importantes em biotecnologia é a lipase, classificadas como triacilglicerol acilhidrolases (E.C.3.1.1.3), são muito utilizadas em processos oleoquímicos, formulação de detergentes, síntese orgânica e indústria alimentícia. Por esse fato, são constantes objetos de estudo e pesquisa (SAID; PIETRO, 2014).

Considerando-se as aplicações industriais, torna-se vantajoso utilizar enzimas na forma imobilizada, uma vez que são mais estáveis e podem ser facilmente recuperadas do meio reacional, possibilitando economia no custo global do processo. Os métodos de imobilização variam desde a adsorção física sobre o suporte até a encapsulação em matrizes sol-gel (BON; FERRARA; CORVO, 2008). 
A aplicação de enzimas imobilizadas hoje tem sido prejudicada pela utilização de suportes caros, limitando o processo. Portanto, encontrar um suporte barato e prontamente disponível para a imobilização da enzima é essencial para o desenvolvimento de novos biocatalisadores imobilizados (BORNSCHEUER, 2012).

Um método bastante utilizado é o de ligação covalente, que consiste na ligação química entre regiões ativas do suporte e de fragmentos dos aminoácidos que constituem a proteína. Dessa forma, é produzida uma enzima mais estável que atua sob condições reacionais bastante amplas (PAULA, 2011).

No entanto, o bom desempenho de um biocatalisador imobilizado relaciona-se também à escolha adequada do suporte de imobilização. Destaque especial é dado ao pó de sabugo de milho. Este material é propício para utilização como suporte, pois é composto basicamente por lignina e celulose que apresentam regiões propensas a interagir com os aminoácidos de proteínas (BASSAN et al., 2016). Além disso, vale ressaltar que o Brasil é um dos maiores produtores de milho do mundo. Segundo a Companhia Nacional de Abastecimento (Conab), na safra 2014/2015 a produção desse vegetal rendeu 84,7 milhões de toneladas (MIRANDA, 2016). Portanto, a geração de resíduos agrícolas também é volumosa, o que faz com que o uso do pó de sabugo de milho como suporte de imobilização de enzimas agregue valor à este resíduo.

Neste contexto, este trabalho teve por objetivo imobilizar lipase de Aspergillus niger em pó de sabugo de milho, por ligação covalente multipontual, e caracterizar o derivado imobilizado resultante com relação aos valores ótimos de pH, temperatura e estabilidade.

\section{MATERIAIS E MÉTODOS}

\subsection{Materiais}

A lipase de Aspergillus niger foi obtida da Novozymes e os reagentes para a imobilização foram da Sigma Chemicals (St Louis, MO, USA). Os demais reagentes químicos foram de grau analítico.

\subsection{Métodos}

Imobilização: Para a imobilização da lipase no suporte pó de sabugo de milho-Glioxil (PSM-Glioxil) o Pó de sabugo de milho foi funcionalizado, de acordo com Bassan et al., (2016). A imobilização foi realizada na proporção de $1 \mathrm{~g}$ do suporte, previamente preparado, para $10 \mathrm{~mL}$ de solução enzimática $(5 \mathrm{mg} / \mathrm{mL}$ de tampão bicarbonato $100 \mathrm{mmol} / \mathrm{L} \mathrm{pH} \mathrm{10,0).} \mathrm{A}$ suspensão foi suavemente agitada em rolo agitador a temperatura ambiente $\left(25^{\circ} \mathrm{C}\right)$, durante 24 h. Depois disso, o derivado foi reduzido com boro-hidreto de sódio $(1 \mathrm{mg} / \mathrm{mL})$ por $30 \mathrm{~min}$ e depois lavado com água destilada e tampão de atividade. Para avaliar a porcentagem de imobilização, amostras do sobrenadante foram periodicamente retiradas e a proteína residual foi medida.

Rendimento de imobilização: $O$ rendimento é um parâmetro para determinar a eficiência do processo de imobilização, sendo mais eficiente na medida que se consiga imobilizar a maior quantidade de enzima possível. Após a imobilização da lipase, realizou-se a determinação do rendimento de imobilização pela seguinte equação: 


$$
R I=\frac{P I-P F}{P F} \times 100
$$

Onde: $\mathrm{RI}=$ Rendimento $(\%) ; \mathrm{PI}=$ Proteína inicial $(\mathrm{mg} / \mathrm{mL})$ livre; PF = Proteína final do sobrenadante $(\mathrm{mg} / \mathrm{mL})$.

Atividade Hidrolítica: Foi determinada pelo método titulométrico, utilizando como substrato óleo de oliva $(5 \% \mathrm{p} / \mathrm{v})$ emulsionado em goma arábica $(5 \% \mathrm{p} / \mathrm{v})$ e tampão fosfato $(25 \mathrm{mM}, \mathrm{pH} 7,0)$. Uma unidade de atividade lipolítica foi definida como a quantidade de enzima capaz de liberar $1 \mu \mathrm{mol}$ de ácido graxo por min de reação nas condições do ensaio (PAULA, 2012).

Caraterização: $\mathrm{O} \mathrm{pH}$ de máxima atividade foi determinado a $40^{\circ} \mathrm{C}$ em diferentes faixas de $\mathrm{pH}(3-8,0)$ em tampão Mcllvaine. Temperatura de máxima atividade foi avaliada a temperaturas na faixa de $25-70^{\circ} \mathrm{C}$. A estabilidade ao $\mathrm{pH}$ foi estudada incubando a enzima a $40^{\circ} \mathrm{C}$ por 1 hora variando o $\mathrm{pH}$ de 3,0-8,0. A determinação da termoestabilidade das enzimas livre e imobilizada foi avaliada determinando-se atividade residual após incubação das enzimas na ausência de substrato a temperaturas variando de $25-70^{\circ} \mathrm{C}$ por 1 hora. Dosagem de proteína foi medido pelo método de Bradford, M., $1976 \mathrm{com}$ absortividade = 2,7086 (mg.mL $)^{-}$ da curva analítica.

\section{RESULTADOS E DISCUSSÃO}

\subsection{Imobilização}

De acordo com a figura 1, pode-se observar que a enzima em estudo apresentou nas primeiras 2 horas de imobilização uma diminuição no teor de proteína para $85 \%$, obtendo assim $15 \%$ de imobilização neste período de tempo. Ao final das 24 horas, a proteína presente no sobrenadante caiu para $61 \%$, caracterizando um rendimento final de imobilização de $39 \%$, permitindo assim, sua imobilização covalente multipontual.

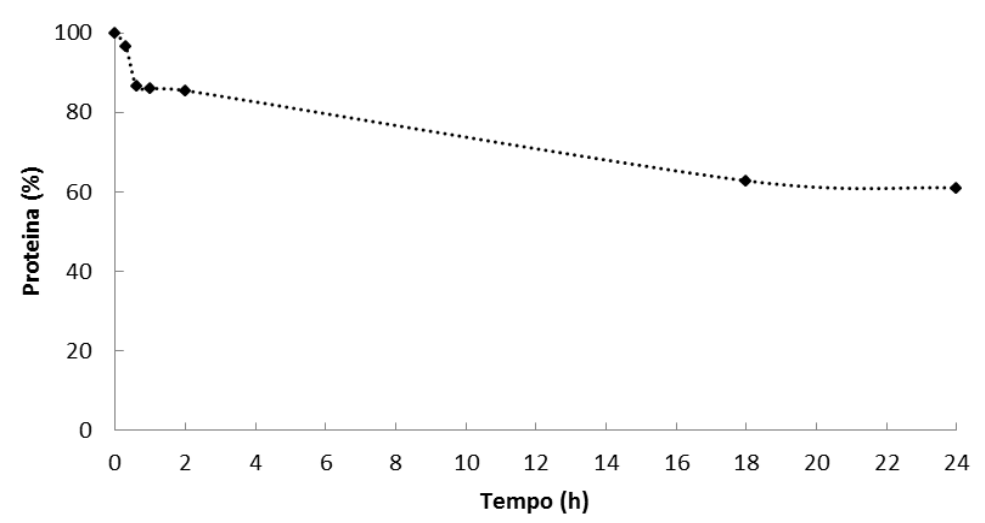

Figura 1. Perfil de imobilização da lipase de Aspergillus niger 


\subsection{Temperatura de máxima atividade.}

A figura 2 mostra que quando imobilizada, a enzima apresenta temperatura ótima em $35^{\circ} \mathrm{C}$, enquanto a livre $45^{\circ} \mathrm{C}$. Esta diferença pode ser explicada devido a maior estabilidade que as enzimas imobilizadas apresentam, exigindo menos temperatura para atingirem seu máximo poder catalítico.

Figura 2 - Atividade relativa em função da temperatura da enzima livre e imobilizada

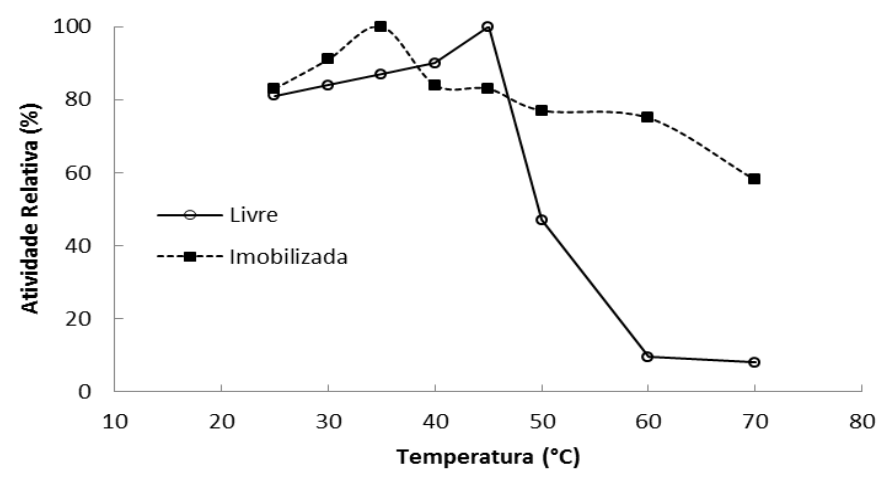

\section{3 pH ótimo}

A Figura 3 mostra o efeito do $\mathrm{pH}$ na atividade das enzimas livre e imobilizada. Houve redução da sensibilidade da enzima ao pH após a imobilização. Em pH 6,5 ambas enzimas apresentaram atividade ótima. Entretanto, a enzima livre apresentou somente $20 \%$ de atividade no $\mathrm{pH} 8$, enquanto a atividade da enzima imobilizada foi de $50 \%$.

Figura 3 - Atividade relativa em função do pH da enzima livre e imobilizada

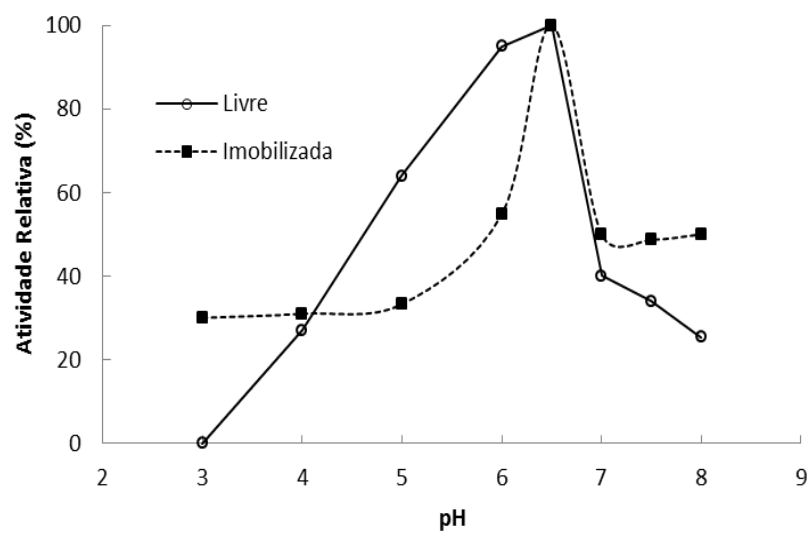

\subsection{Estabilidade}

A Figura 4 apresenta os valores de atividade residual das enzimas livre e imobilizada após 1 hora de exposição a diferentes temperaturas na ausência do substrato. É bastante clara a maior termoestabilidade da enzima imobilizada. Após 1 hora a $45^{\circ} \mathrm{C}$, a enzima livre reteve $70 \%$ da atividade inicial, enquanto a enzima imobilizada reteve $100 \%$ da atividade inicial. O 
aumento da estabilidade pode se dar em função da estabilização da estrutura da proteína ou simplesmente porque enzimas imobilizadas estão menos acessíveis a agentes desnaturantes (Marconi, 1989). Essa estabilidade é regida pelo número e a natureza das ligações formadas entre a enzima e o suporte; pelo grau de confinamento da enzima ao suporte; pelo microambiente formado entre a enzima e o suporte e as condições de imobilização (Cao, 2005).

Figura 4 - Termoestabilidade da lipase de Aspergillus niger livre e imobilizada em pó de sabugo de milho

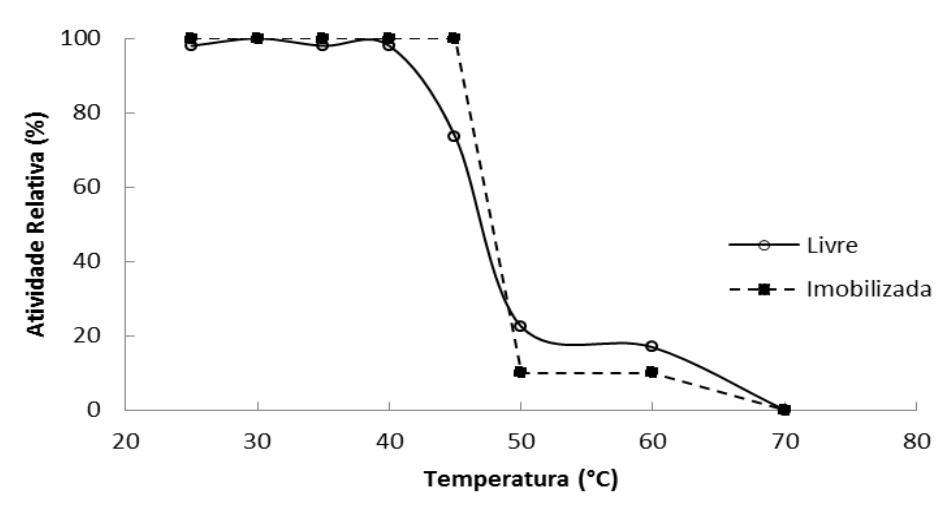

A Figura 5 apresenta os valores de atividade residual das enzimas livre e imobilizada após 1 hora de exposição a diferentes pH's na ausência do substrato. É notável a maior estabilidade frente ao $\mathrm{pH}$ da enzima imobilizada. Após 1 hora a $\mathrm{pH}$ 7,5 a enzima livre reteve $40 \%$ da atividade inicial, enquanto a enzima imobilizada reteve $63 \%$ da atividade inicial. $\mathrm{O}$ aumento da estabilidade pode se dar em função da estabilização da estrutura da proteína. Essa estabilidade é regida pelo número e a natureza das ligações formadas entre a enzima e o suporte (Cao, 2005).

Figura 5 - Estabilidade em $\mathrm{pH}$ da lipase de Aspergillus niger livre e imobilizada em pó de sabugo de milho

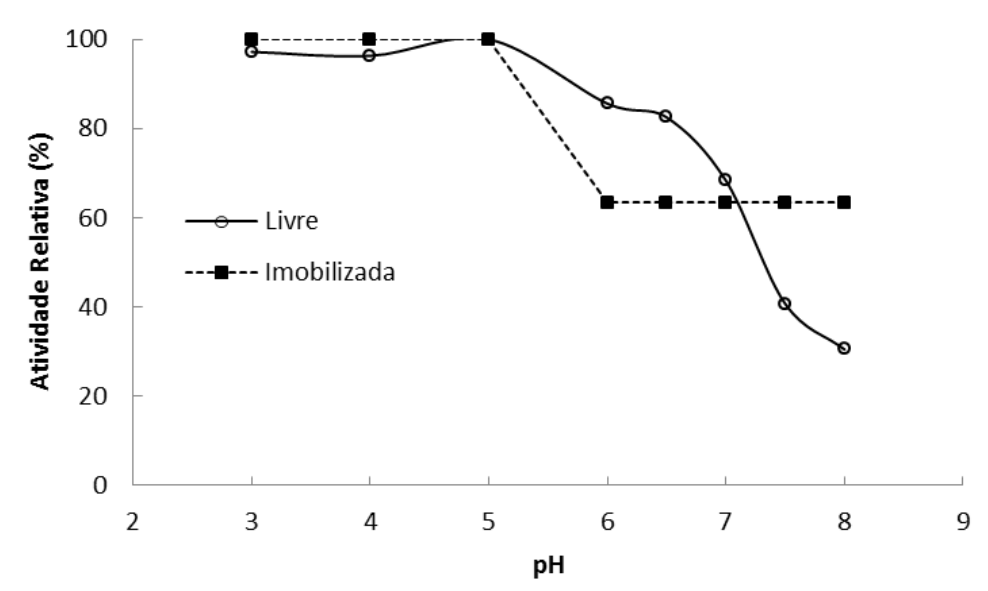




\section{CONCLUSÃO}

Os resultados mostraram que o sabugo de milho-glioxil é um suporte promissor para imobilização da lipase de A. niger. Através do desenvolvimento deste trabalho foi possível a determinação dos valores ótimos de $\mathrm{pH}(6,5)$ e temperatura $\left(35^{\circ} \mathrm{C}\right)$ do derivado imobilizado, que apresentou ótima estabilidade quando comparado com a enzima livre.

\section{REFERÊNCIAS}

BASSAN, J. C. et al. Immobilization of Trypsin in Lignocellulosic Waste Material to Produce Peptides with Bioactive Potential from Whey Protein. Materials, v. 9, n. 357, mai. 2016.

BORNSCHEUER, UT; HUISMAN, GW; KAZLAUSKAS, RJ; LUTZ, S; MOORE, JC and ROBINS, K. 2012. Nature, 485: 185-194.

BON, E. P. S.; FERRARA, M. A.; CORVO, M. L. Enzimas em Biotecnologia: Produção, Aplicações e Mercado. 1. ed. Rio de Janeiro: Interciência, 2008. 506 p.

CAO, L. 2005. Immobilised enzymes: science or art? Curr Opin Chem Biol 9(2): 217-226.

MARCONI, W. 1989. Immobilized enzymes: their catalytic behaviour and their industrial and analytical applications. Reactive Polymers , 11, 1-19.

MIRANDA, R. A. Um Ano de Extremos para a Produção de Milho. Embrapa, nov. 2016. Disponível em: <https://www.embrapa.br/busca-de-noticias/-/noticia/17979608/artigo---2016um-ano-de-extremos-para-a-producao-de-milho.>. Acesso em: 7 fev. 2017.

PAULA, A. V. Reestruturação da gordura do leite por interesterificação enzimática empregando lipase imobilizada: otimização das condições reacionais e operacionais. 2011. 184 f. Tese (Doutorado em Ciências) - Escola de Engenharia de Lorena, Universidade de São Paulo, Lorena, 2012.

SAID, S.; PIETRO, R. C. L. R. Enzimas como agentes biotecnológicos. 2. ed. Ribeirão Preto: Legis Summa, 2014. 383 p. 